Research Article

\title{
Effects of Two-Phase Treatment with the Herbst and Preadjusted Edgewise Appliances on the Upper Airway Dimensions
}

\author{
Woei Li Koay, Yanqi Yang, Christine Shuk Kwan Tse, and Min Gu \\ Orthodontics, Faculty of Dentistry, The University of Hong Kong, 34 Hospital Road, Sai Ying Pun, Hong Kong \\ Correspondence should be addressed to Min Gu; drgumin@hku.hk
}

Received 25 September 2015; Revised 16 February 2016; Accepted 25 February 2016

Academic Editor: Tucker Woodson

Copyright (C) 2016 Woei Li Koay et al. This is an open access article distributed under the Creative Commons Attribution License, which permits unrestricted use, distribution, and reproduction in any medium, provided the original work is properly cited.

Aims. To assess the effects of two-phase treatment with the Herbst and the preadjusted edgewise appliances on upper airway dimensions and to investigate the correlation between changes in the upper airway dimensions and skeletal morphologies. Methods. A total of 27 Chinese male adolescents aged $12.8 \pm 1.3$ years were selected. Lateral cephalograms were collected to assess the skeletal morphology and upper airway dimensions. Results. Following Herbst appliance treatment, the upper airway space was significantly enlarged, with the retropalatal (U-MPW) increasing by $1.1 \pm 1.6 \mathrm{~mm}(P<0.001)$, the retroglossal (PASmin) increasing by $1.3 \pm 2.9 \mathrm{~mm}(P<0.05)$, and the hypopharynx (V-LPW) enlarging by $1.6 \pm 3.0 \mathrm{~mm}(P<0.01)$. PASmin was found to show a negative correlation to the mandibular plane angle (MnPl-SN) by $r=-0.413(P<0.05)$. There was no significant change $(P>0.05)$ in upper airway dimensions during the second-phase treatment. Conclusions. Herbst appliance treatment increased the oropharyngeal and hypopharyngeal airway dimensions among adolescents with Class II malocclusion, and the effects were maintained throughout the second treatment phase with a preadjusted edgewise appliance. There was a negative correlation between the change in the depth of the retroglossal pharynx and the mandibular plane angle.

\section{Introduction}

Mandible advancement devices (MADs) are known to improve the airway space, particularly in adult patients with sleep apnoea and snoring problems [1-3]. MADs are nonsurgical approaches and are currently recognised as the primary noncontinuous positive airway pressure (CPAP) therapy [1] used to treat mild to moderate obstructive sleep apnoea (OSA) and daytime sleepiness, and for those who do not tolerate CPAP $[2,4]$. MADs are effective in patients over 65 years old with good dental health [5]. They advance the mandible forward by holding the teeth to increase the patency of the airway space and thus reduce snoring, improve the quality of sleep, and reduce daytime sleepiness. There is no single type of MAD that influences perceived treatment efficacy above others, but the majority of studies have shown improved subjective outcomes with MAD. This suggests that mandibular advancement is a crucial design feature of oral appliance therapy for obstructive sleep apnoea syndrome [69].
Functional appliances have similar effects to MADs, also advancing the mandible to a forward position [10, 11]. They are commonly used among skeletal Class II children with retrognathic mandibles $[12,13]$. When the muscles attached to the mandible are stretched, these appliances have been shown to help reposition the mandible by remodelling the condyle, and the force generated is sufficient to induce secondary growth at the condylar head, therefore changing the growth pattern of the face $[14,15]$. Functional appliances are also believed to affect airway correction by preventing the tongue from dropping backward and blocking the airway when the mandible is held in a forward position [16]. TheHerbst appliance is a fixed functional appliance that is cemented temporarily onto the teeth without relying on patient compliance and may help with pharyngeal space correction $[11,16]$.

Approximately $2-10 \%$ of school-aged children suffer from sleep-disordered breathing (SDB) [17], and constriction of the pharyngeal airway space is common in these patients [18]. Daytime sleepiness is also related to SDB, which is potentially associated with certain Class II tendency malocclusions, such 
as an increased overjet and bilateral Class II molar relationship [19]. Therefore, an early diagnosis is recommended for children who potentially have this sleep problem, enabling them to receive proper intervention.

The aims of this study are to assess the effects of the Herbst and the preadjusted edgewise appliances on upper airway dimensions among adolescents with Class II malocclusion and to investigate the correlation between changes in the upper airway dimensions and the skeletal morphology after two-phase treatment with these appliances.

\section{Materials and Methods}

This study was approved by the Institutional Review Board of the University of Hong Kong/Hospital Authority, Hong Kong West Cluster (IRB Reference number: UW 12-405).

2.1. Sample Size Calculation. Calculation of the sample size was based on the ability to detect a clinically relevant difference in the changes of the depth of the retroglossal pharyngeal airway space (PASmin) by $1.87 \mathrm{~mm}$ after the functional appliance treatment [13]. On this basis, with an alpha of 0.05 and a study power of $0.80,26$ subjects were required for the study group.

2.2. Subjects. A sample of Chinese male subjects who underwent orthodontic treatment at the Prince Philip Dental Hospital from 1999 to 2010 was recruited.

The inclusion criteria were 1 , male; 2 , in the age range of 11 to 14 at pretreatment $(T 0) ; 3$, no permanent teeth extracted; 4, having received two-phase treatment with a Herbst appliance and a preadjusted edgewise appliance; 5, complete lateral cephalograms obtained at pretreatment (T0) and immediate post-Herbst (T1) and postedgewise treatment (T2). The exclusion criteria for the study were patients with craniofacial syndromes and cleft lips or palates.

Based on the selection criteria, consecutive cases that had undergone orthodontic treatment at the Prince Philip Dental Hospital from 1999 to 2010 were screened, and 27 male patients were selected for the study. The mean average age of the subjects who began the Herbst treatment was $12.8 \pm 1.3$ years. They completed phase 1 treatment by the mean age of $13.9 \pm 1.5$ years, which was followed by the preadjusted edgewise treatment. The mean of the two-phase treatment time duration was $3.0 \pm 1.1$ years. The same sample was used in a previous study [20] to evaluate the change of mandibular position.

2.3. Cephalometric Analysis. Lateral cephalometric radiographs were collected and analysed using CASSOS software (Soft Enable Technology Limited, Hong Kong, China). After calibration, the landmarks were identified by the same examiner (KWL), and the parameters for the skeletal morphology and upper airway dimensions were obtained. Landmarks [21] representing the four parts of the upper airway, namely, the nasopharyngeal (PM-UPW), retropalatal (U-MPW), retroglossal (PASmin), and hypopharyngeal (VLPW), were used to assess the dimension changes of the upper airway. Skeletal morphology was represented by four

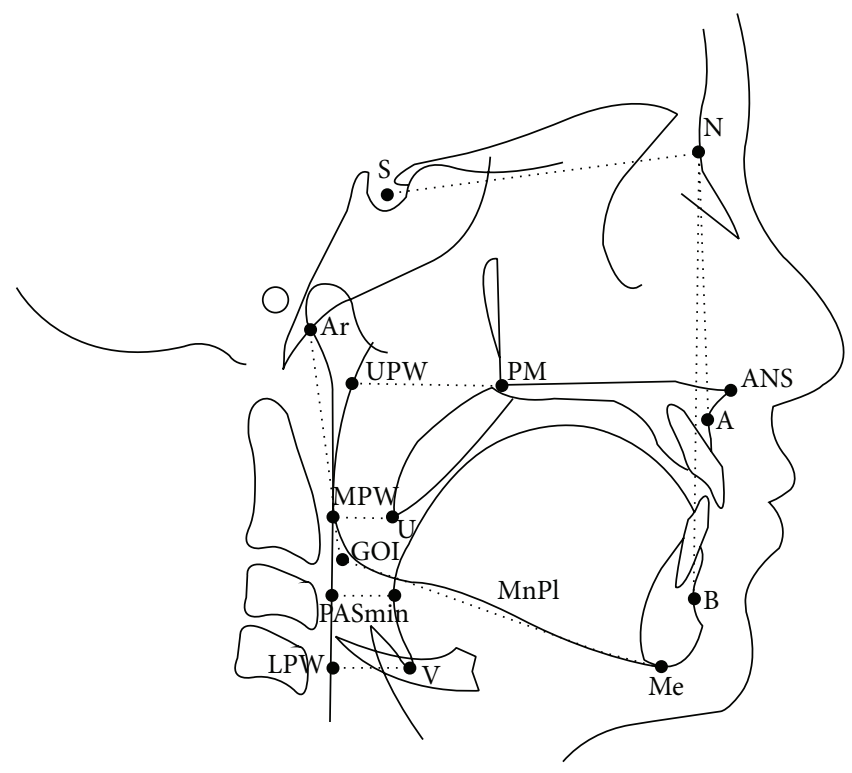

FIgURE 1: Landmarks and measurements of the upper airway and skeletal morphology.

different parameters, SNA, SNB, ANB, and mandibular angle $(\mathrm{MnPl} / \mathrm{SN})$, to assess the sagittal and vertical changes of the skeletal pattern (Table 1, Figure 1).

Pretreatment (T0), post-Herbst treatment (T1), and postedgewise treatment (T2) lateral cephalograms were analysed, and the changes in the depth of the four upper airway spaces (PM-UPW, U-MPW, PASmin, and V-LPW) and skeletal morphology (ANB angle, SNA angle, SNB angle, and MnPl/SN angle) were used to determine the skeletal and pharyngeal space response to treatment with a functional appliance followed by a preadjusted edgewise appliance (Table 3).

Comparisons were made between patients in the same group using different time points at pretreatment (T0), postHerbst treatment (T1), and postedgewise treatment (T2) to assess the changes. Those due to functional appliance therapy from the pretreatment stage to the post-Herbst stage were measured as $(T 1-T 0)$ between the two time points. The mean difference change found in the postedgewise stage was then compared $(T 2-T 1)$ to assess the changes brought by the second stage treatment. The overall treatment effects (T2-T0) were obtained by comparing the pretreatment stage and the end treatment of the preadjusted edgewise appliance (Table 3).

2.4. Method Errors. Error studies were performed on 25 randomly selected lateral cephalograms, and the measurements were repeated after a two-week time interval by the same examiner (KWL). Error studies were carried out using Dalberg's formula and a paired $t$-test (Table 2). Dalberg's formula [22] was as follows: $\mathrm{ME}=\sqrt{\sum d^{2} / 2 n}$, where $\mathrm{ME}$ is the method error, $d$ is the difference between the first and the second measurements, and $n$ is the number of repeated measurements. The difference between the repeated measurements was not statistically significant in the paired $t$-test and did not exceed $1 \mathrm{~mm}$ for the linear and $1^{\circ}$ for 
TABLE 1: Definition of cephalometric landmarks and measurements of Figure 1.

\begin{tabular}{|c|c|}
\hline & Definition \\
\hline \multicolumn{2}{|l|}{ Landmarks } \\
\hline ANS & Anterior nasal spine, the tip of the median, sharp bony process of the maxilla \\
\hline $\mathrm{PM}$ & Pterygomaxillary, the intersection between the nasal floor and the posterior contour of the maxilla [29] \\
\hline UPW & Upper pharyngeal wall, point of intersection of the line NL to the posterior pharyngeal wall \\
\hline MPW & Middle pharyngeal wall, intersection of the perpendicular line from $U$ to the posterior pharyngeal wall \\
\hline LPW & Lower pharyngeal wall, intersection of the perpendicular line from $V$ to the posterior pharyngeal wall \\
\hline $\mathrm{U}$ & Uvula, the tip of the uvula \\
\hline $\mathrm{V}$ & Vallecula, the intersection of the epiglottis and the base of the tongue \\
\hline S & Center of the sella turcica \\
\hline $\mathrm{N}$ & Nasion, the deepest point in the concavity of nasofrontal suture \\
\hline A & $\begin{array}{l}\text { A point, the deepest point in the concavity of the anterior maxilla between the anterior nasal spine and the } \\
\text { alveolar crest }\end{array}$ \\
\hline $\mathrm{B}$ & $\begin{array}{l}\text { B point, the deepest point in the concavity of the anterior mandible between the alveolar crest and the } \\
\text { pogonion }\end{array}$ \\
\hline Gn & Gnathion, the most anteroinferior point on the bony chin \\
\hline $\mathrm{Me}$ & Mention, the most inferior point on the body chin \\
\hline $\mathrm{Ar}$ & The intersection of the posterior border of the ramus with inferior surface of the cranial base \\
\hline GOI & $\begin{array}{l}\text { Gonial intersection, the intersection of the mandibular plane with a plane through Ar, posterior and along } \\
\text { the portion of the mandibular ramus inferior to it [30] }\end{array}$ \\
\hline NL & Nasal line, line joining the ANS and PM \\
\hline $\mathrm{MnPl}$ & Mandibular plane, line joining Me and GOI \\
\hline \multicolumn{2}{|l|}{ Measurements } \\
\hline PM-UPW (mm) & Depth of the nasopharyngeal airway space from PM to UPW \\
\hline U-MPW (mm) & Depth of the oropharyngeal airway space from $U$ to MPW \\
\hline PASmin $(\mathrm{mm})$ & $\begin{array}{l}\text { Shortest distance between the base of the tongue and the posterior pharyngeal wall, the narrowest sagittal } \\
\text { airway space }\end{array}$ \\
\hline V-LPW (mm) & Depth of the hypopharyngeal airway space from V to LPW \\
\hline SNA $\left({ }^{\circ}\right)$ & Angle between the $\mathrm{S}-\mathrm{N}$ line and the $\mathrm{N}-\mathrm{A}$ line \\
\hline $\mathrm{SNB}\left({ }^{\circ}\right)$ & Angle between the S-N line and the N-B line \\
\hline $\operatorname{ANB}\left({ }^{\circ}\right)$ & Angle between the N-A line and the N-B line \\
\hline $\mathrm{MnPl} / \mathrm{SN}\left({ }^{\circ}\right)$ & Mandibular plane angle, the angle between the $\mathrm{MnPl}$ and the S-N line \\
\hline
\end{tabular}

TABLE 2: Method error analyses of landmark input using Dahlberg's formula and paired $t$-test.

\begin{tabular}{lcc}
\hline Measurements & Dahlberg's formula & $t$-test $P$ value \\
\hline Depth of upper airway $(\mathrm{mm})$ & & \\
PM-UPW & 0.981 & 0.233 \\
U-MPW & 0.448 & 0.180 \\
PASmin & 0.362 & 0.301 \\
V-LPW & 0.680 & 0.084 \\
\hline Skeletal morphology $\left(^{\circ}\right)$ & & \\
SNA & 0.506 & 0.072 \\
SNB & 0.356 & 0.088 \\
ANB & 0.497 & 0.561 \\
MP-SN & 0.847 & 0.287 \\
\hline
\end{tabular}

the angular measurements (Table 2), which were acceptable levels of error.
2.5. Statistical Analysis. The normality of the data appeared to be valid (Shapiro-Wilk test). Comparative statistical analysis of the data was carried out using a paired $t$-test to analyse the significant differences between the changes during the treatment periods $(T 1-T 0, T 2-T 1$, and $T 2-T 0)$ (Table 3$)$. The probability value $P<0.05$ was considered significant, with $P<0.01$ and $P<0.001$ considered highly significant. The correlation between the changes in the pharyngeal space and the skeletal morphology was analysed using the Spearman rank correlation, and the statistical significance was set at the level of $P<0.05$ (Table 4). SPSS software (IBM SPSS Statistics version 20, IBM Corp.) was used to carry out the statistical analyses.

\section{Results}

3.1. Changes in Skeletal Morphology. The paired $t$-test revealed a statistical increase in SNB of $2.4 \pm 2.0$ degrees $(P<$ $0.001)$ and $A N B$ was reduced by $1.7 \pm 2.2$ degrees $(P<0.001)$ 


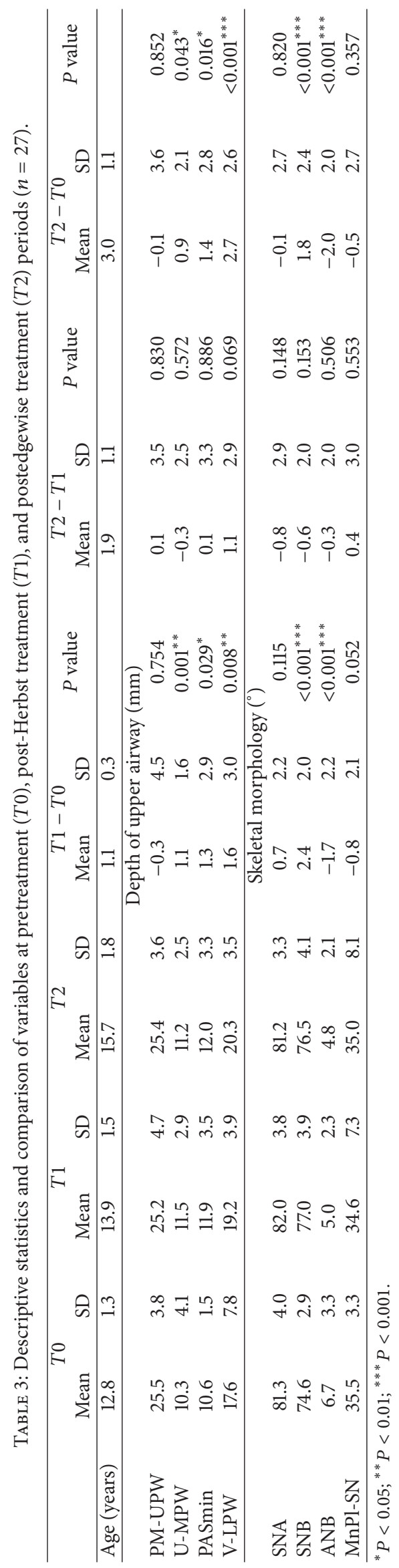




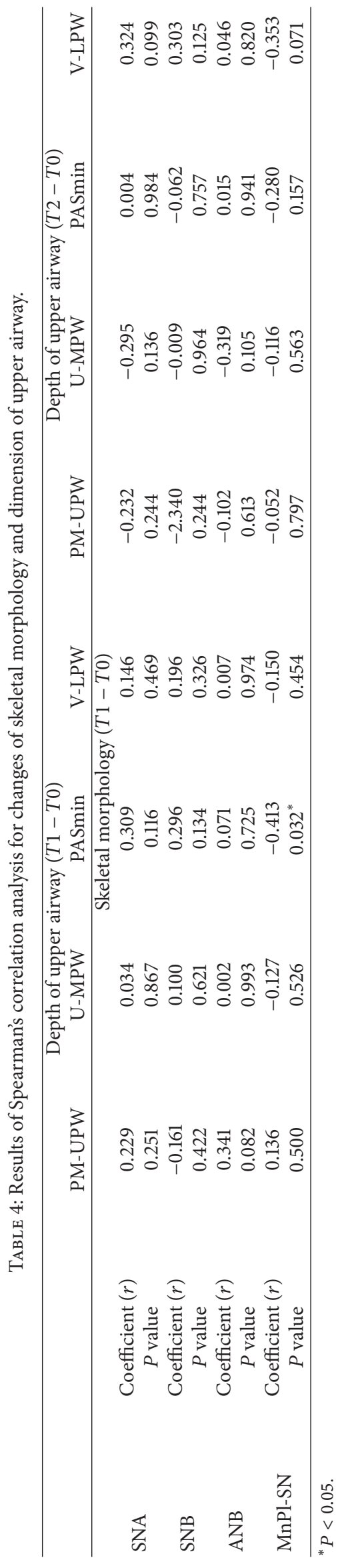


after the Herbst treatment $(T 1-T 0)$. The changes in SNA and the $\mathrm{MnPl} / \mathrm{SN}$ angle were not statistically significant. None of the variables showed a statistically significant change during the second phase of the preadjusted edgewise appliance treatment $(T 2-T 1)$. However, the data showed a similar change pattern at the completion of the two-phase treatment $(T 2-T 0)$, which was $1.8 \pm 2.4$ degrees $(P<0.001)$ and $-2.0 \pm 2.0$ degrees $(P<0.001)$, respectively (Table 3$)$.

3.2. Changes in the Upper Airway Dimensions. The upper airway space was significantly enlarged by a similar amount after the Herbst treatment (T1-T0) (Table 3$)$. The retropalatal region (U-MPW) increased by $1.1 \pm 1.6 \mathrm{~mm}(P<0.001)$, the retroglossal region (PASmin) by $1.3 \pm 2.9 \mathrm{~mm}(P<0.05)$, and the hypopharynx region (V-LPW) by $1.6 \pm 3.0 \mathrm{~mm}(P<0.01)$. There was an insignificant reduction in the nasopharynx region (PM-UPW) $(P>0.05)$. The improvement in the upper airway dimensions was maintained throughout the secondphase treatment with the preadjusted edgewise appliance $(T 2-T 1)$. The overall therapeutic effect $(T 2-T 0)$ was that $\mathrm{V}$ LPW had the highest dimensional changes, of $2.7 \pm 2.6 \mathrm{~mm}$ $(P<0.001)$, followed by the increase of PASmin by $1.4 \pm$ $2.8 \mathrm{~mm}(P<0.05)$ and U-MPW by $0.9 \pm 2.1 \mathrm{~mm}(P<0.05)$ (Table 3).

3.3. Correlations between the Changes in the Skeletal Morphology and Upper Airway Dimensions. In the main, the changes in both the skeletal morphology and airway dimensions occurred in the Herbst treatment phase, so changes in the first phase $(T 1-T 0)$ and also those after the two-stage treatment $(T 2-T 0)$ was completed were further analysed to investigate the correlation between the skeletal morphology and upper airway dimensions (Table 4).

There was no correlation between the changes in the upper airway dimensions and the sagittal skeletal morphology after the two-phase treatment $(T 2-T 0)$ (Table 4$)$ in the analysis. However, PASmin showed a negative correlation to the mandibular plane angle $(\mathrm{MnPl} / \mathrm{SN})$ by $r=-0.413(P<$ $0.05)$ after the Herbst treatment $(T 1-T 0)$ (Table 4).

\section{Discussion}

4.1. The Influence of the Herbst on the Upper Airway Dimensions. Our study showed that, during the Herbst appliance treatment, SNB was increased; the airway dimensions were effectively increased in similar amount from the medium pharyngeal space of the oropharynx to the hypopharynx, which suggested that the Herbst effectively and consistently influenced most areas of the upper airway during its active phase. The result was found to be in line with previous studies [10]. Schütz et al. [10] showed that the Herbst improved nocturnal breathing in the short term by increasing the airway space associated with the correction of mandibular retrognathism. Other studies also reported on the effectiveness of different type of functional appliances on the increase of pharyngeal space in long term follow-up $[23,24]$.

The Herbst appliance is considered an effective functional appliance for altering airway dimensions due to its full-time action and the fact that it does not rely on patient compliance [25]. The reduction of SNA by 0.8 degrees in postedgewise stage ( $T 2-T 1)$ was due to the remodelling of the anterior alveolar bone after retraction of upper labial segment especially in extraction cases for the dental camouflage of the Class II skeletal pattern [26]. The small reduction of SNA was not statistically significant to affect the distance between the soft palate and the posterior pharyngeal wall.

The overall treatment effect on the upper airway dimensions in the postedgewise stage $(T 2-T 0)$ was increased and the greatest dimensional change was found to be at the lowest part of the airway level which was the hypopharynx region. This may be due to some treatment plus growth effect although the change was minimal and not significant. However, it is unethical to have an untreated control group to distinguish between the appliance effect and growth effect with the age match.

It is well known that the different genders will reach their peak growth period at different times [21, 23, 27]. Males showed significantly greater height growth and increase in pharyngeal length although there are no significant changes between genders in long term follow-up [23]. Therefore, we attempted to minimise the variability of our results due to this different growth factor by selecting only Hong Kong Chinese boys as our study subjects.

4.2. Correlations between the Changes of the Skeletal Morphology and the Changes of the Upper Airway Dimension. The present study also found a significant correlation $(P<$ $0.05)$, although weak $(r=-0.413)$, between the changes in the airway dimensions and the vertical changes in the mandibular plane angle. The change in the retroglossal pharyngeal space (PASmin) was inversely correlated with the mandibular plane angle $(\mathrm{MnPl} / \mathrm{SN})$ after the first phase of treatment with the Herbst appliance $(T 1-T 0)$. That is, when the mandibular was advanced during the Herbst treatment, there were an increase at the medium pharyngeal airway and a reduction in the mandibular plane angle. There was similar finding by Hänggi et al. [23] of weak correlation $(r=-0.22$, $P=0.22$ ) between the changes of pharyngeal space and the angular changes of $\mathrm{MnPl} / \mathrm{SN}$ when the growth was taken into consideration. However, Han et al. [24] showed a significant interaction effect between the upper oropharyngeal region, gonial angle, and mandibular plane angle $(P<0.05)$. Therefore, it is important to obtain good vertical control of the skeletal pattern, which could benefit airway modification, particularly when treating skeletal CII cases.

\subsection{Lateral Cephalometric Analysis and Alternative Proce-} dures. Lateral cephalogram records can only provide a twodimensional assessment, and computed tomography (CT) [28] or magnetic resonance imaging (MRI) will be more appropriate to give a three-dimensional (volume) assessment of the airway space.

The measurements acquired from both modalities (lateral cephalogram and CT) are reliable and reproducible, but CT gives a better assessment of the cross-sectional dimensions of the airway space [28]. However, proper justification is crucial before exposing patients to the higher radiation of CT 
investigation, which may not result in significant changes in the treatment modalities.

In this study, we were not able to relate our findings to the sleep quality improvement of the patients. The patients received treatment to correct the retrognathic mandible and did not complain of airway problems nor did they undergo polysomnography (PSG). Retrospectively, we note that there was no special instruction given to the patient to locate the tongue or determine the actual tongue position in the lateral cephalogram records, which could affect the findings of our study.

Due to ethical limitation, this study did not include a control group with untreated Class II malocclusion. The changes following treatment should be seen as combination effects of growth and treatment.

\section{Conclusions}

The oropharyngeal and hypopharyngeal airway dimensions were increased among adolescents presenting with Class II malocclusion during Herbst appliance treatment, and the effects were maintained throughout the second treatment phase with a preadjusted edgewise appliance. There was a negative correlation between the change in the depth of the retroglossal pharynx and the mandibular plane angle.

\section{Competing Interests}

The authors declare that they have no competing interests.

\section{Acknowledgments}

The authors would like to express their sincere thanks to Dr. Rhonda for keeping the patient records, Professor Samman for organising the use of computers equipped with CASSOS software, and Miss Samantha for her statistical assistance. This study was funded by the Seed Funding Programme for Basic Research no. 201410159010 of the University of Hong Kong.

\section{References}

[1] W. J. Randerath, J. Verbraecken, S. Andreas et al., "Non-CPAP therapies in obstructive sleep apnoea," European Respiratory Journal, vol. 37, no. 5, pp. 1000-1028, 2011.

[2] M. Marklund, J. Verbraecken, and W. Randerath, "Non-CPAP therapies in obstructive sleep apnoea: mandibular advancement device therapy," European Respiratory Journal, vol. 39, no. 5, pp. 1241-1247, 2012.

[3] H. M. Hou, K. Sam, U. Hägg et al., "Long-term dentofacial changes in Chinese obstructive sleep apnea patients after treatment with a mandibular advancement device," Angle Orthodontist, vol. 76, no. 3, pp. 432-440, 2006.

[4] D. P. White and S. Shafazand, "Mandibular advancement device vs CPAP in the treatment of obstructive sleep apnea: are they equally effective in short term health outcomes?" Journal of Clinical Sleep Medicine, vol. 9, no. 9, pp. 971-972, 2013.

[5] M. Marklund and K. A. Franklin, "Treatment of elderly patients with snoring and obstructive sleep apnea using a mandibular advancement device," Sleep and Breathing, vol. 19, no. 1, pp. $403-$ 405, 2015.

[6] A. Ahrens, C. McGrath, and U. Hägg, "A systematic review of the efficacy of oral appliance design in the management of obstructive sleep apnoea," European Journal of Orthodontics, vol. 33, no. 3, pp. 318-324, 2011.

[7] H. Gotsopoulos, C. Chen, J. Qian, and P. A. Cistulli, "Oral appliance therapy improves symptoms in obstructive sleep apnea: a randomized, controlled trial," American Journal of Respiratory and Critical Care Medicine, vol. 166, no. 5, pp. 743748, 2002.

[8] C. D. Johnston, I. C. Gleadhill, M. J. Cinnamond, J. Gabbey, and D. J. Burden, "Mandibular advancement appliances and obstructive sleep apnoea: a randomized clinical trial," European Journal of Orthodontics, vol. 24, no. 3, pp. 251-262, 2002.

[9] A. Mehta, J. Qian, P. Petocz, M. A. Darendeliler, and P. A. Cistulli, "A randomized, controlled study of a mandibular advancement splint for obstructive sleep apnea," American Journal of Respiratory and Critical Care Medicine, vol. 163, no. 6, pp. 1457-1461, 2001.

[10] T. C. B. Schütz, G. C. Dominguez, M. P. Hallinan, T. C. A. Cunha, and S. Tufik, "Class II correction improves nocturnal breathing in adolescents," Angle Orthodontist, vol. 81, no. 2, pp. 222-228, 2011.

[11] H. M. Lawton, J. M. Battagel, and B. Kotecha, "A comparison of the Twin Block and Herbst mandibular advancement splints in the treatment of patients with obstructive sleep apnoea: a prospective study," European Journal of Orthodontics, vol. 27, no. 1, pp. 82-90, 2005.

[12] A. K. Jena, S. P. Singh, and A. K. Utreja, "Effectiveness of twin-block and Mandibular Protraction Appliance-IV in the improvement of pharyngeal airway passage dimensions in Class II malocclusion subjects with a retrognathic mandible," Angle Orthodontist, vol. 83, no. 4, pp. 728-734, 2013.

[13] M. M. Özbek, T. U. Toygar Memikoglu, H. Gögen, A. A. Lowe, and E. Baspinar, "Oropharyngeal airway dimensions and functional-orthopedic treatment in skeletal Class II cases," Angle Orthodontist, vol. 68, no. 4, pp. 327-336, 1998.

[14] S. Ruf and H. Pancherz, "Temporomandibular joint growth adaptation in Herbst treatment: a prospective magnetic resonance imaging and cephalometric roentgenographic study," European Journal of Orthodontics, vol. 20, no. 4, pp. 375-388, 1998.

[15] S. Ruf and H. Pancherz, "Temporomandibular joint remodeling in adolescents and young adults during Herbst treatment: a prospective longitudinal magnetic resonance imaging and cephalometric radiographic investigation.," American Journal of Orthodontics and Dentofacial Orthopedics, vol. 115, no. 6, pp. 607-618, 1999.

[16] G. Kinzinger, K. Czapka, B. Ludwig, B. Glasl, U. Gross, and J. Lisson, "Effects of fixed appliances in correcting Angle Class II on the depth of the posterior airway space : FMA vs. Herbst appliance-a retrospective cephalometric study," Journal of Orofacial Orthopedics, vol. 72, no. 4, pp. 301-320, 2011.

[17] J. H. Wildhaber and A. Moeller, "Sleep and respiration in children: time to wake up!”, Swiss Medical Weekly, vol. 137, no. 49-50, pp. 689-694, 2007.

[18] I. Ceylan and H. Oktay, "A study on the pharyngeal size in different skeletal patterns," American Journal of Orthodontics and Dentofacial Orthopedics, vol. 108, no. 1, pp. 69-75, 1995.

[19] M. Gu, Y. Yang, A. C. Ho, R. W. Wong, U. Hägg, and C. P. McGrath, "Craniofacial characteristics related to daytime 
sleepiness screened by the paediatric daytime sleepiness scale," The Open Dentistry Journal, vol. 9, no. 1, pp. 31-40, 2015.

[20] R. N. Y. Cheung, U. Hägg, R. W. K. Wong, C. Liao, and Y. Yang, "Change of mandibular position during two-phase orthodontic treatment of skeletal Class II in the Chinese population," The Scientific World Journal, vol. 2015, Article ID 804831, 16 pages, 2015.

[21] M. Gu, C. P. J. McGrath, R. W. K. Wong, U. Hägg, and Y. Yang, "Cephalometric norms for the upper airway of 12-yearold Chinese children," Head and Face Medicine, vol. 10, no. 1, article no. 38, 2014.

[22] "Statistical Methods for Medical and Biological Students," British Medical Journal, vol. 2, no. 4158, pp. 358-359, 1940.

[23] M. P. Hänggi, U. M. Teuscher, M. Roos, and T. A. Peltomäki, "Long-term changes in pharyngeal airway dimensions following activator-headgear and fixed appliance treatment," European Journal of Orthodontics, vol. 30, no. 6, pp. 598-605, 2008.

[24] S. Han, Y. J. Choi, C. J. Chung, J. Y. Kim, and K.-H. Kim, “Longterm pharyngeal airway changes after bionator treatment in adolescents with skeletal Class II malocclusions," The Korean Journal of Orthodontics, vol. 44, no. 1, pp. 13-19, 2014.

[25] K. O’Brien, J. Wright, F. Conboy et al., "Effectiveness of treatment for class II malocclusion with the Herbst or Twin-block appliances: a randomized, controlled trial," American Journal of Orthodontics and Dentofacial Orthopedics, vol. 124, no. 2, pp. 128-137, 2003.

[26] H. Pancherz, "The mechanism of Class II correction in Herbst appliance treatment. A cephalometric investigation," American Journal of Orthodontics, vol. 82, no. 2, pp. 104-113, 1982.

[27] W. J. Ursi, C. A. Trotman, J. A. McNamara Jr., and R. G. Behrents, "Sexual dimorphism in normal craniofacial growth," Angle Orthodontist, vol. 63, no. 1, pp. 47-56, 1993.

[28] S. Kaur, S. Rai, and M. Kaur, "Comparison of reliability of lateral cephalogram and computed tomography for assessment of airway space," Nigerian Journal of Clinical Practice, vol. 17, no. 5, pp. 629-636, 2014.

[29] T. Lyberg, O. Krogstad, and G. Djupesland, "Cephalometric analysis in patients with obstructive sleep apnoea syndrome. I. Skeletal morphology," Journal of Laryngology and Otology, vol. 103, no. 3, pp. 287-292, 1989.

[30] M. L. Riolo, R. E. Moyers, J. A. McNamara Jr., and W. S. Hunter, An Atlas of Craniofacial Growth, Center for Human Growth and Development, The University of Michigan, 1974. 


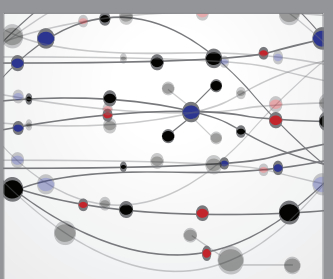

The Scientific World Journal
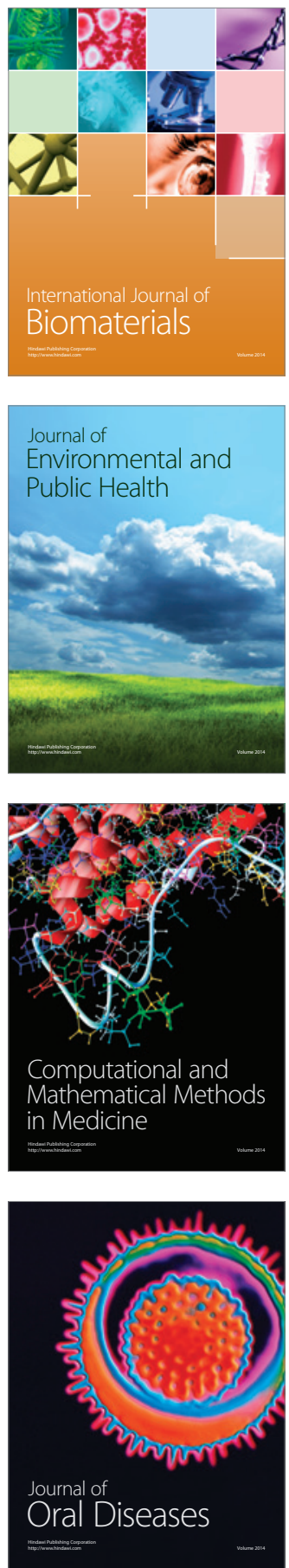
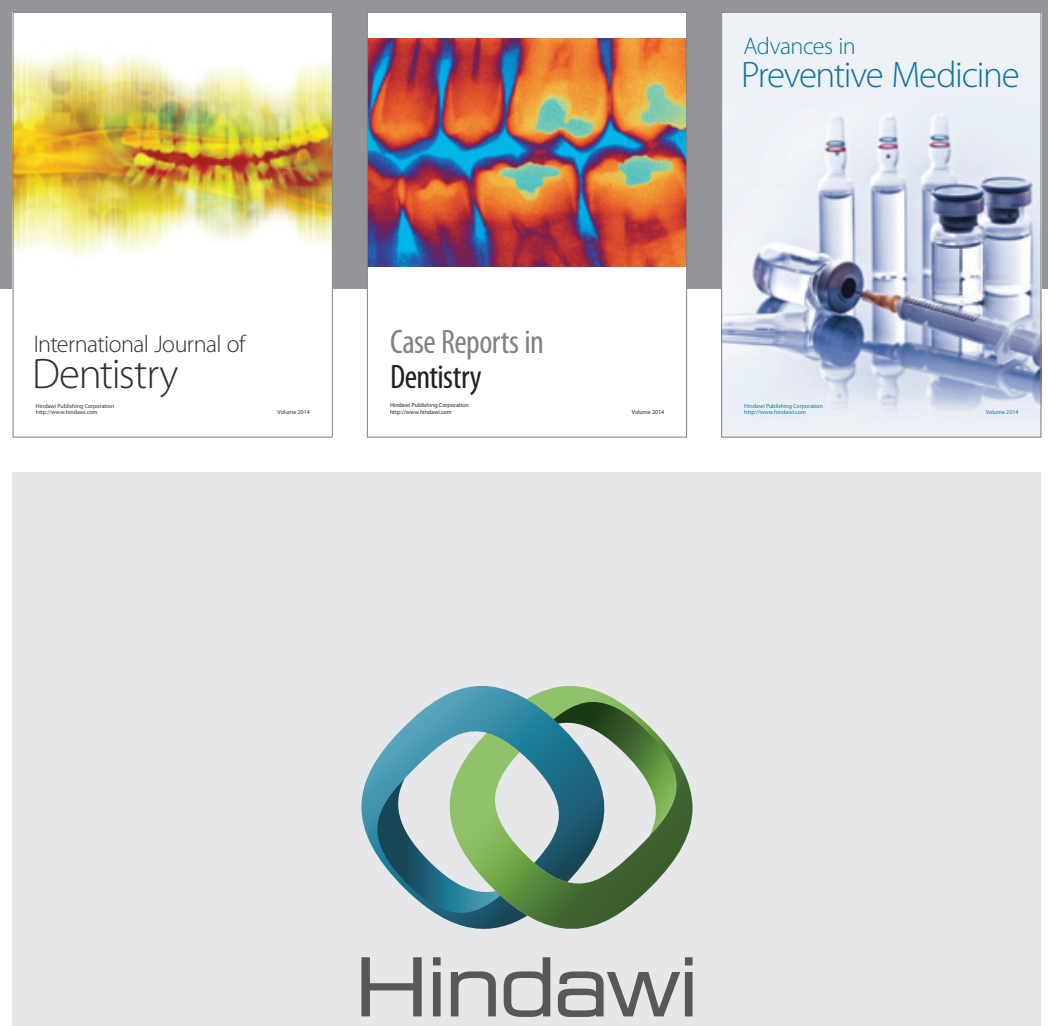

Submit your manuscripts at

http://www.hindawi.com
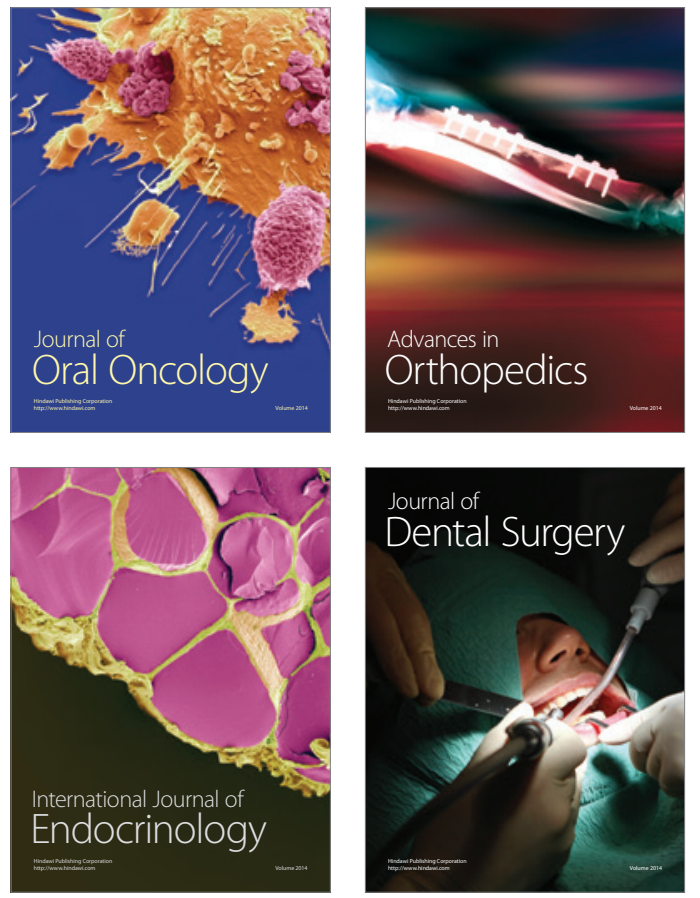
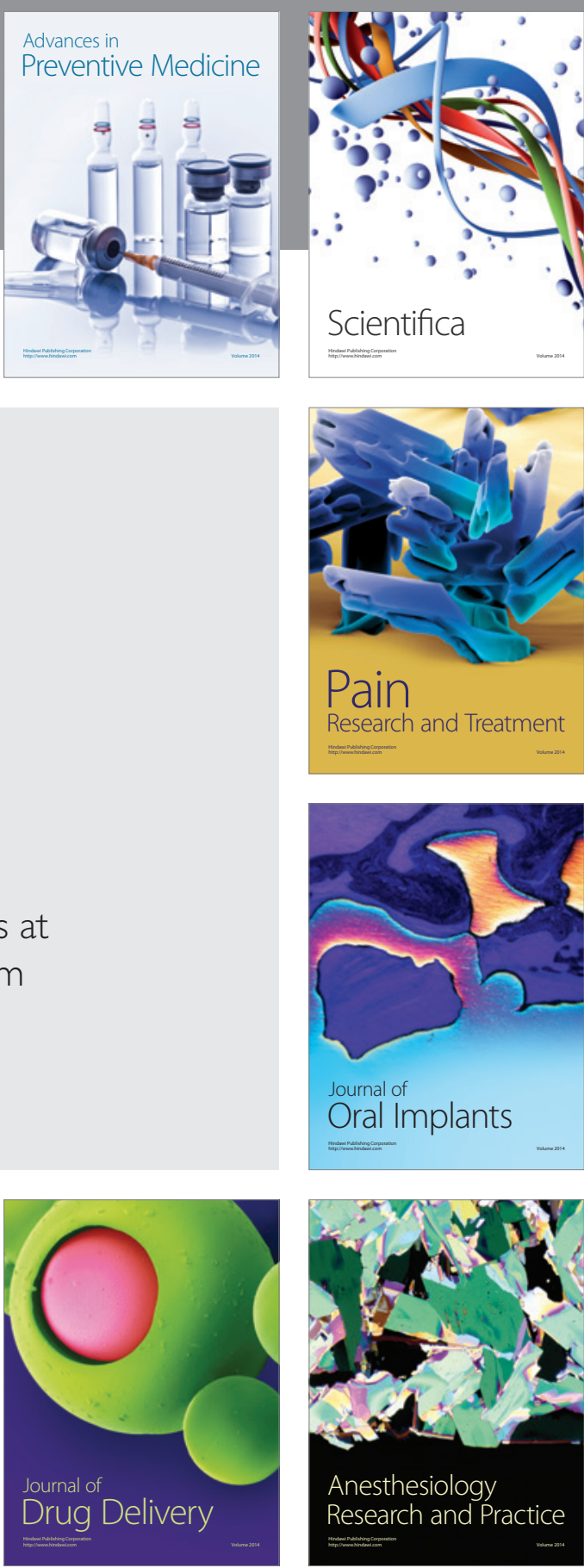

Scientifica
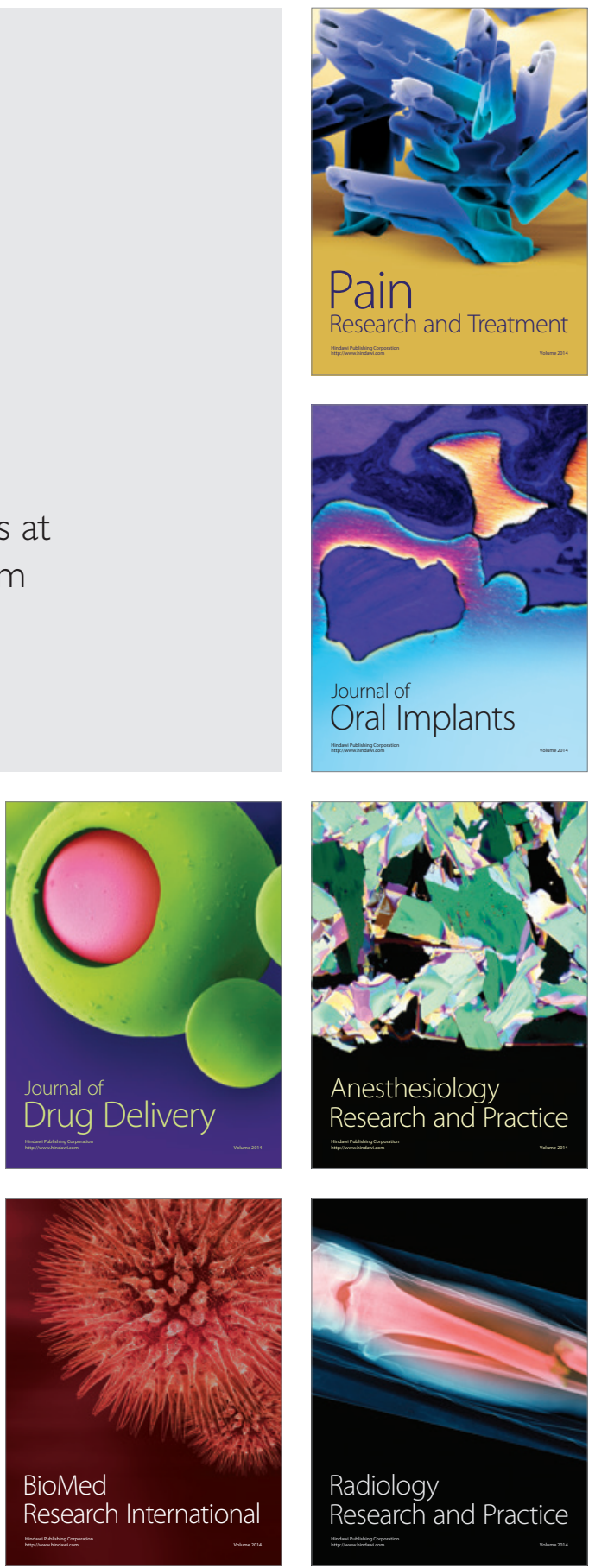